\title{
Em Busca de um Ensino Sociolinguístico de Língua Portuguesa no Brasil $^{1}$
}

\author{
In Search of a Teaching Sociolinguistic Portuguese Language \\ IN BRAZIL
}

\author{
Talita de Cássia Marine* \\ Juliana Bertucci Barbosa**
}

Resumo: Um dos obstáculos no ensino de língua portuguesa como língua materna é o tratamento da variação linguística e, fundamentalmente, os saberes gramaticais permeados por diferentes normas linguísticas. Assim, neste artigo, propomos algumas reflexões a respeito do cenário atual do ensino de língua portuguesa no Brasil, apresentando uma revisão teórica sobre o tema, sobretudo acerca dos conceitos de crença e atitudes linguísticas em estudos sociolinguísticos e em documentos do governo brasileiro. Reunimos, ainda, alguns resultados de pesquisas já realizadas sobre crenças e atitudes linguísticas e citamos três fatores que evidenciam que o ensino de língua portuguesa no Brasil ainda está distante de um ensino reflexivo e de uma pedagogia culturalmente sensível. Para provar tais fatores, mencionamos exemplos de falas e atividades de discentes de escolas de Ensino Fundamental e Médio,

\footnotetext{
* Doutora em Linguística e Língua Portuguesa pela Universidade Estadual Paulista, Campus Araraquara (2009). Professora Doutora Adjunto III - UFU. Contato: talita.marine@gmail.com.

** Doutora em Linguística e Língua Portuguesa pela Universidade Estadual Paulista, Campus Araraquara (2008). Professora Doutora Adjunto IV - UFTM. Contato: julianabertucci@gmail.com.

${ }^{1}$ Pesquisa ligada ao PROFLETRAS (Programa Mestrado Profissional em Letras) e PIBID (Programa Institucional de Bolsa de Iniciação à Docência), fomentado pela Capes (Coordenação de Aperfeiçoamento de Pessoal de Nível Superior).
} 
bem como de alunos do curso de Letras. Dessa forma, neste artigo apontamos o quanto ainda é desafiador pensar numa concepção sociolinguística de ensino de língua portuguesa no Brasil.

Palavras-chave: Ensino. Sociolinguística. Crenças e atitudes linguísticas.

Abstract: One of the barriers in teaching Portuguese as mother tongue is the treatment of linguistic variation and fundamentally grammatical knowledge permeated by different linguistic norms. So in this article, we propose some reflections on the current situation of the Portuguese language teaching in Brazil, presenting a literature review on the topic, especially about the concepts of belief and linguistic attitudes studies sociolinguistic and documents the Brazilian government. Still we gather some results of previous studies on language attitudes and beliefs and we quote three factors that show that the Portuguese-speaking education in Brazil is still far from a reflective teaching and culturally sensitive pedagogy. To prove such factors mentioned, we mentioned examples of speeches and activities of students of primary and secondary schools as well as letters of course students. Thus, in this article, we point out how it is still challenging to think of a sociolinguistic conception of Portuguese language teaching in Brazil.

Keywords: Education. Sociolinguistics. Belief and Linguistic Attitude.

\section{Considerações Iniciais}

A perspectiva de língua adotada pelos Parâmetros Curriculares Nacionais (PCN), documento do governo brasileiro que orienta o ensino de língua portuguesa na Educação Básica, concebe-a como uma realidade dinâmica que se dá nas situações concretas de uso. Em consonância com tal postura e coadunando-nos com o que afirmam Martins, Vieira e Tavares (2014, p. 9), um

... dos maiores desafios das aulas de Português diz respeito, sem dúvida, ao tratamento da variação linguística e, fundamentalmente, aos saberes gramaticais - permeados por diferentes normas linguísticas - que devem estar presentes na escola. [...] A multifacetada realidade brasileira, 
em todas as suas expressões socioculturais, reflete-se na produtiva e saudável convivência de diversas variedades linguísticas da vida escolar.

Partindo dessas discussões, buscaremos, neste artigo, propor algumas reflexões que julgamos essenciais quando se trata de ensino de língua portuguesa no Brasil - questões sempre envoltas por inquietações relacionadas às maneiras como este ensino continua sendo praticado na maioria de nossas escolas ${ }^{2}$. Para isso, procuramos: (a) realizar uma revisão teórica sobre o assunto, especialmente sobre os conceitos de crença e atitudes linguísticas, em estudos sociolinguísticos e em documentos do governo brasileiro; (b) apresentar alguns resultados de pesquisas já realizadas sobre crenças e atitudes linguísticas com discentes das escolas pesquisadas e com alunos de Letras; (c) discutir fatores, com base em relatos de alunos de escolas públicas e formandos do curso de Letras, causadores da distância entre o ensino de língua portuguesa na Educação Básica no Brasil e a pedagogia culturalmente sensível às variações socioculturais e linguísticas.

Por meio desta pesquisa, acreditamos contribuir para a reflexão acerca de algumas questões que estão por detrás da falta de sintonia entre os PCN de Língua Portuguesa e a realidade da prática docente nas escolas brasileiras, buscando contribuir, assim, para maior conscientização dos problemas que permeiam este fato e dos obstáculos a serem enfrentados em prol de um ensino produtivo e comprometido com a realidade sociolinguística de nosso país. Para atingirmos nossos objetivos, inicialmente apresentaremos algumas questões teóricas a fim de respaldar nossas reflexões em busca de uma prática de ensino/aprendizagem de língua portuguesa mais reflexiva e atenta à diversidade linguística do Português Brasileiro.

2 Quando dizemos "continua sendo praticado" e atribuímos a isso "inquietações", partimos do pressuposto de que o ensino de língua portuguesa, tal como vem sendo executado na maior parte de nosso país, mostra-se como algo ultrapassado, ineficiente e quase que completamente desconexo das orientações dos Parâmetros Curriculares Nacionais (PCN), especialmente no que concerne à concepção de língua defendida e sugerida por tais documentos, bem como à perspectiva sociolinguística de ensino de língua que se mostra de modo bastante claro e necessário nesses documentos, a fim de se atender às demandas e às características de nossa Nação, inquestionavelmente pluricultural, pluriétnica e multilíngue (CAVALCANTI, 1999). 


\section{Sociolinguística: reflexões iniciais}

Se partirmos do pressuposto de que linguagem e sociedade estão ligadas de modo inquestionável, poderia parecer que o termo "sociolinguística" é uma redundância, uma vez que a linguagem seria, então, um fenômeno essencialmente social. Entretanto, as coisas não são tão simples assim, afinal, a relação entre linguagem e sociedade, embora seja reconhecida por todos, nem sempre é assumida como determinante aos e nos estudos da linguagem. E é justamente aí que se justifica o nome para esta ramificação dos estudos linguísticos, uma vez que, para a Sociolinguística, os aspectos sociais são essenciais e determinantes aos estudos da língua.

Assim, podemos dizer que o objeto de estudo da Sociolinguística é a língua em uso, aquela utilizada pelos falantes nas mais diversas situações de interação social, seja ela realizada pela fala ou pela escrita. É a língua real que, assim como todas as línguas naturais do mundo, exibe variações em seus mais diferentes níveis - fonológico, morfológico, sintático, lexical, semântico etc. -, já que nenhuma língua se apresenta como uma entidade homogênea; toda língua natural se constitui por (e como) um conjunto de variedades, não existindo supremacia linguística entre as línguas e nem entre as variedades de uma mesma língua.

O que existe, sim, é uma valoração social em relação às variedades linguísticas por parte do Homem, que acaba conferindo a algumas línguas e variedades da língua, prestígio, e a outras, estigmas e preconceitos. A esse respeito, Gnerre (1998, p. 6), em seu livro Linguagem, escrita e poder, já nos chamava a atenção para o fato de que "uma variedade lingüística 'vale' o que 'valem' na sociedade os seus falantes, isto é, vale como reflexo do poder e da autoridade que eles têm nas relações econômicas e sociais". Ciente de tudo isso, a Sociolinguística encara a diversidade linguística não como um problema, mas como uma característica constitutiva da própria língua.

Julgamos que esta maneira de se compreender e lidar com a diversidade linguística seja a primeira grande contribuição da Sociolinguística ao ensino de uma língua natural. Partindo desse pressuposto e focando nossas reflexões ao ensino de língua portuguesa no Brasil, entendemos que um dos maiores desafios do professor esteja relacionado à real consideração e abordagem da diversidade cultural, étnica, social e, sobretudo, linguística existente em nosso país. 
Acreditamos que todos esses aspectos que constituem a realidade de nossas salas de aula precisam ser considerados a fim de que possamos promover um ensino realmente produtivo (TRAVAGLIA, 2009), pautado na reflexão crítica e contextualizada da língua em uso: real, dinâmica e multifacetada. E, nesse ponto, mais uma contribuição da Sociolinguística se evidencia ao ensino de língua portuguesa, uma vez que o reconhecimento natural das variedades da língua permite ao educador e ao educando estabelecer diversas semelhanças entre o que se convencionou chamar de "norma culta" e "norma popular".

\section{Sociolinguística e Ensino: a busca por um ensino produtivo}

Postas estas primeiras reflexões, podemos nos centrar no foco deste artigo: o ensino de língua portuguesa tal como se mostra atualmente tradicional, prescritivo e alienado da diversidade linguística - e como acreditamos que deveria e poderia se configurar - interativo, produtivo e engajado pela perspectiva sociolinguística de língua. Nesse sentido, um primeiro ponto a ser destacado diz respeito ao fato de que

... um dos maiores desafios enfrentados pelo professor de português nos níveis fundamental e médio é qual saberes gramaticais devem ser efetivamente acionados na escola. É comum confundir o ensino de português com ensino de uma norma padrão homogeneizadora e abstrata, que em nada se aproxima dos diferentes usos efetivos da língua nas mais variadas situações de expressão sociocultural no país. Isso leva a dois grandes problemas, correlacionados entre si, que em muito têm prejudicado o ensino de português como língua materna: o preconceito linguístico e a falta de orientação quanto à multifacetada diversidade linguística brasileira a ser considerada em sala de aula. (MARTINS; VIEIRA; TAVARES, 2014, p. 7).

Todos esses desafios, dificuldades e problemas para que possam começar a ser enfrentados, precisam, entre outras coisas, ser motivo de reflexões e indagações dos docentes de língua portuguesa que, como já mencionado no início deste artigo, precisam saber qual a concepção de língua 
que assumem e como desempenham a sua prática docente, que tipo de ensino almejam desenvolver em suas aulas e, principalmente, quais são os objetivos a serem alcançados por meio de suas aulas. Sem que essas questões estejam claras para o professor, as dificuldades enfrentadas no ambiente escolar - que não são poucas -, serão ainda mais complexas e difíceis de serem combatidas e minimizadas.

Cabe destacar que, já na apresentação dos PCN, afirma-se o seguinte:

O domínio da língua, oral e escrita, é fundamental para a participação social efetiva, pois é por meio dela que o homem se comunica, tem acesso à informação, expressa e defende pontos de vista, partilha ou constrói visões de mundo, produz conhecimento. Por isso, ao ensinála, a escola tem a responsabilidade de garantir a todos os seus alunos o acesso aos saberes lingüísticos, necessários para o exercício da cidadania, direito inalienável de todos. (BRASIL, 1998, p. 15).

É evidente que a perspectiva de língua adotada pelos PCN concebe-a como uma realidade dinâmica e multifacetada. Logo, dentro dessa perspectiva, "a língua não pode mais ser definida como um espaço lógico e abstrato de possibilidades, pré-existente à ação, e que a ação apenas atualizaria" (MONDADA, 1998, p. 132), afinal, “a língua não pré-existe; ela se dá emergencialmente nas situações concretas de uso" (MARCUSCHI, 2007b, p. 96), e, por ser um sistema de signos histórico e social, possibilita ao homem significar o mundo e a realidade que o cerca.

Partindo dessas considerações, a escola e seus professores, sobretudo os de língua portuguesa, precisam se livrar de alguns mitos permeados por declarado preconceito de caráter linguístico como, e principalmente, os de que existe uma única forma "certa" de falar e escrever e que a escrita é o espelho da fala. Afinal, equívocos desta ordem contribuem para que milhares de professores de Língua Portuguesa acreditem que seja imperativo "consertar" a fala do aluno para evitar que ele escreva "errado". Crenças como essas

... produziram uma prática de mutilação cultural que, além de desvalorizar a forma de falar do aluno, tratando sua comunidade como 
se fosse formada por incapazes, denota desconhecimento de que a escrita de uma língua não corresponde inteiramente a nenhum de seus dialetos, por mais prestígio que um deles tenha em um dado momento histórico. (BRASIL, 1998, p. 26).

\section{Crenças, Atitudes Linguísticas e o Ensino de Língua Portuguesa}

Dada algumas das reflexões postas até o presente momento neste artigo, parece-nos claro que o conhecimento e a discussão acerca de dois conceitos mostram-se essenciais ao se tratar de ensino de língua portuguesa no Brasil: os de crença e atitude linguística. Crença e atitude linguística estão de tal forma relacionadas que não se pode tratá-las separadamente, uma vez que a primeira influencia a segunda. Partilhamos das ideias de Cyranka ${ }^{3}$ (2007, p. 25) e acreditamos que, no ensino de língua, o que nos interessa é a "a crença sobre", ou seja, "a posição em que os professores e os alunos colocam os objetos (língua, linguagem, variação e aprendizagem lingüística) dentro da dimensão avaliativa, posição essa que, em última instância, leva à atitude deles em relação a esses objetos". Neste caso, é relevante ressaltar que essa "dimensão avaliativa", citada pela autora, é exatamente a crença que se possui acerca de tais "objetos", também expressos por ela. Desse modo, a atitude linguística pode ser compreendida como resultado de convicções que o aluno tem sobre a língua e outros elementos relacionados a ela, como o ensino e a variação.

Em vista disso, considerações importantes sobre crença e atitude linguística foram revistas e serão apresentadas, sucintamente, nas subseções seguintes, com a finalidade de evidenciar a importância desses conceitos em nosso trabalho.

${ }^{3}$ Cyranka (2007, p. 24) destaca que a crença de um indivíduo em relação a um o objeto pode revelar a posição em que esse indivíduo coloca o objeto dentro da dimensão avaliativa. Por isso, a autora esclarece a distinção entre "crença em" e "crença sobre", decidindo pelo emprego desta última em sua pesquisa. Cyranka, retomando as definições de Santos (1996), afirma que "crença em" está relacionada à crença em um objeto (ou seja, somente em sua existência) e "crença sobre (o objetivo)" está relacionada à natureza do objeto, à sua maneira de existir e à sua relação com outros objetos. 
As crenças, apesar de bastante estudadas em diversas áreas do conhecimento, como Psicologia, Filosofia, Antropologia, Sociologia e Linguística (GARBUIO, 2006; CYRANKA, 2007), não possuem conceituação pontual, sendo empregadas sob variadas denominações, como explica Garbuio (2006, p. 88):

Elas [as crenças] são estudadas em diversas áreas, além de serem nomeadas de diversas maneiras na literatura. Na Psicologia Social, Woofolk Hoy e Murphy [...] utilizam o termo conhecimento implícito ou tácito [...] Na Psicologia, Rokeach [...] utiliza o termo sistema de crenças $[\ldots]$

Ainda segundo Garbuio, alguns autores no campo da Linguística Aplicada, como Richards e Lockhart (1994, p. 30), igualmente empregam a expressão "sistema de crenças" e compreendem que estas antecedem as "decisões e ações". Barcelos e Abrahão (2006, p. 15-16), por sua vez, descrevem o panorama dos estudos sobre crenças no Brasil e apontam como recentes as análises da relação entre crenças e cognição. Conforme as autoras (p. 17, destaque nosso), atualmente entende-se que o conceito de cognição abarca elementos "tais como capacidade simbólica, o eu, a vontade, crenças e desejo" e que se organiza na "interação social moldada por processos culturais e sociopolíticos”. Mais adiante, no decorrer de suas reflexões, explicita a sua compreensão acerca das crenças:

Entendo crenças, de maneira semelhante a Dewey, como uma forma de pensamento, como construções de realidade, maneiras de ver e perceber o mundo e seus fenômenos, co-construídas em nossas experiências e resultantes de um processo interativo de interpretação e (re) significação. Como tal, crenças são sociais (mas também individuais), dinâmicas, contextuais e paradoxais. (BARCELOS; ABRAHÃO, 2006, p. 18).

Já no âmbito da Sociolinguística, Santos (1996), ao contrário dos linguistas aplicados - que se referem a crenças e ações - relaciona crenças a 
atitudes, definindo a primeira como "convicção íntima, uma opinião que se adota com fé e certeza", e a segunda (atitude) como

... uma disposição, propósito ou manifestação de intento ou propósito. Tomando atitude como manifestação, expressão de opinião ou sentimento, chega-se à conclusão de que nossas reações frente a determinadas pessoas, a determinadas situações, a determinadas coisas seriam atitudes que manifestariam nossas convicções íntimas, ou seja, as nossas crenças em relação a essas pessoas, situações ou coisas. (SANTOS, 1996, p. 8).

$\mathrm{Na}$ tentativa de melhor esclarecer a relação entre atitude e crença, da qual também se ocupa a Sociolinguística, Cyranka (2007, p. 23) expõe questões teóricas sobre a mensuração das atitudes linguísticas que se concentram em duas respectivas linhas: a dos mentalistas e a dos behavioristas. Segundo a linguista, a proposição dos primeiros é a análise das atitudes a partir dos elementos afetivo, cognitivo e conativo, enquanto os segundos defendem a análise exclusivamente sob a ótica afetiva, considerada a avaliativa. Ao prosseguir a exposição sobre a relação aqui apontada, a autora diz:

No entanto, para Rokeach (1968 apud DITTMAR, 1976, p. 181), as atitudes são primariamente constituídas por crenças. Para Fishbein (1965), enquanto as atitudes dizem respeito ao aspecto afetivo do sujeito em relação a determinado objeto, as crenças revelam a dimensão cognitiva e ativa desse mesmo sujeito em relação ao objeto. (CYRANKA, 2007, p. 23).

De posse dessas definições a respeito da relação entre crenças e atitudes, infere-se que as crenças exercem grande influência nas atitudes do sujeito, e estas, por sua vez, manifestam aquelas. Além disso, as crenças são um construto complexo do contexto em que esse sujeito está inserido. Exemplo disso são os estudos de Scherre (2005) sobre variação linguística e mídia, que deram origem ao Doa-se lindos filhotes de poodle - variação lingüistica, mídia e preconceito. Em tal obra, a autora reflete acerca da abordagem preconceituosa da língua (atitudes linguísticas) em publicações do jornal Correio Brasiliense. Numa dessas publicações, a língua portuguesa brasileira sofre processo de desvalorização 
ao ser comparada à de Portugal, como transcreve Scherre na seguinte passagem: "A pessoa que apresenta a seção [...] revela explicitamente este preconceito logo no primeiro parágrafo '[a seção] não deve ser entendida como uma alusão aos nossos irmãos do além-mar, que falam o idioma melhor que os brasileiros"” (SCHERRE, 2005, p. 39).

Esse processo de comparação e valorização do português falado em Portugal, em detrimento do falado no Brasil, é constante nas análises que a autora faz dos conteúdos publicados pelo jornal, revelando que a mídia contribui para a crença de que os brasileiros falam mal o Português, bem como para o preconceito linguístico e a convicção de que é difícil falar e "aprender" a língua portuguesa.

Ainda em relação ao citado conteúdo publicado pelo Correio Brasiliense, Scherre destaca:

A meu ver, o apresentador da seção faz confusão entre língua e discurso político, e suas palavras refletem uma visão equivocada de língua, que nos tem sido passada ao longo dos séculos: a visão de que há línguas estruturalmente melhores do que outras; mais ricas e mais complexas - o que já se sabe que, do ponto de vista da estrutura lingüística, não é verdade. (2005, p. 39).

Cabe destacar que a mídia, assim como outros formadores de opinião, como o professor, tem responsabilidade sobre as crenças construídas pelo brasileiro a respeito de sua própria língua, visto que ele está inserido em um contexto que propicia a aquisição de valores e informações que possibilitam a criação de uma opinião enviezada, de juízos sobre determinado objeto e, nesse caso específico, da língua materna. É nesse sentido que crenças são entendidas como construtos do contexto. Garbuio (2006, p. 90), partilhando dessa mesma convicção, afirma ainda que "[as crenças] são construídas a partir da história do indivíduo e a partir de sua interação com o meio, além de poder admitir graus".

Barcelos e Abrahão, acerca da reflexão da natureza das crenças, igualmente evidenciam o seu caráter contextual nas seguintes proposições:

[As crenças são] Emergentes, socialmente construídas e situadas contextualmente: [...] as crenças não estão dentro de nossas mentes como uma estrutura 
mental pronta e fixa, mas mudam e se desenvolvem à medida que interagimos e modificamos nossas experiências e, somos, ao mesmo tempo modificados por elas. [...] Dessa forma, as crenças incorporam as perspectivas sociais, pois nascem no contexto da interação e na relação com os grupos sociais. (BARCELOS; ABRAHÃO, 2006, p. 19; destaque dos autores).

Portanto, mais que graduais, como afirma Garbuio, as crenças são dinâmicas e podem ser (re)significadas. Nesse sentido, Santos (1996) também acredita que as atitudes, igualmente, são passíveis a mudanças e argumenta que algumas pesquisas já apontaram evidências de que a atitude de um indivíduo pode ser alterada se forem mudadas suas crenças.

Tal como Garbuio (2006) e Santos (1996), acreditamos que as crenças são mutáveis e dinâmicas, por isso podem ser alteradas. Por exemplo, em um contexto de sala de aula em que os alunos afirmam (creem) que a língua portuguesa é "muito difícil" ou então que "falam mal" e "errado" a sua própria língua, se o professor propiciar a discussão sobre esse tema, considerando a variação linguística, essas crenças podem ser (re)significadas.

Ou seja, se os professores passarem a ter uma abordagem mais reflexiva e embasada pelos preceitos da Sociolinguística Educacional ${ }^{4}$, poderemos modificar as crenças dos alunos em relação à língua e, assim, as atitudes em relação às suas próprias variedades linguísticas poderão ser

${ }^{4}$ O termo Sociolinguística Educacional foi cunhado por Bortoni-Ricardo (2004); evidentemente que os estudos da Sociolinguística em interface com o ensino de língua portuguesa são anteriores, mas foi esta pesquisadora que propôs uma ramificação dentro da Sociolinguística - a Sociolinguística Educacional -, a fim de conduzir de modo mais sistematizado as contribuições da Sociolinguística ao ensino/aprendizagem de língua portuguesa no Brasil, dialogando com o que Erickson (1987) apontava como "pedagogia culturalmente sensível”, conceitos estes que vão ao encontro do que Faraco (2015) denomina, por sua vez, como "pedagogia da variação linguística”, defendendo, em linhas gerais, que é possível e necessário desenvolver um ensino de língua portuguesa no Brasil que considere como legítimas, "corretas", as variedades linguísticas que os alunos trazem do seio de seus lares para o ambiente escolar, e que lhes ensine as variedades cultas da língua, a fim de que possam ampliar sua competência comunicativa. 
alteradas também. Por isso, o professor de língua portuguesa deve levar em consideração as crenças linguísticas de seus alunos em suas aulas e, a partir desse (re)conhecimento, propor atividades que reflitam sobre o uso da língua nos mais diversos contextos de uso, acionando, para isso, tal como sugerido pelos PCN de língua portuguesa (BRASIL, 1998), o trabalho sistematizado e contextualizado de diferentes gêneros discursivos, tanto na modalidade escrita quanto na falada, realizados segundo diferentes níveis de monitoramento estilístico.

Cabe relembrar que o estudo das atitudes e crenças linguísticas está relacionado ao tema da avaliação, que por sua vez é discutida por Weinreich, Labov e Herzog (2009) e por Labov $(1972,1974)$, sendo considerada uma das cinco questões que despertaram o seu interesse para o estudo da variação/ mudança linguística:

Nos referiremos a estas [...] questões e a seus problemas associados como as questões de fatores condicionantes, transição, encaixamento e avaliação. [...] À luz das respostas a estas, podemos avançar uma quinta questão [...] a que fatores se pode atribuir a implementação das mudanças? (WEINREICH; LABOV; HERZOG, 2009, p. 36-37).

Cyranka (2007), ao realizar um estudo sobre atitudes e crenças linguísticas, diz que um dos interesses da Sociolinguística consiste na análise desses dois aspectos:

O estudo das atitudes e das crenças lingüísticas é uma das tarefas que a Sociolingüística se propõe [...] e se refere ao problema da avaliação, relativo aos julgamentos subjetivos do usuário quanto à sua própria variedade lingüística e à dos seus interlocutores. Portanto os trabalhos que discutem a rejeição da escola em relação ao dialeto do aluno e vice-versa devem ser tratados sob a ótica do problema da avaliação linguística. (CYRANKA, 2007, p. 17).

Partilhando das afirmações da autora, acreditamos que a avaliação linguística visa à compreensão dos julgamentos dos falantes sobre a língua e também sobre a variedade deles próprios e de seus interlocutores. Essa 
avaliação (ou atitude) é de ordem subjetiva e por isso são analisados os pensamentos, sentimentos e reações dos falantes quando em contato com os "estímulos linguísticos" que lhes são expostos. Esta é a concepção de atitude linguística adotada neste artigo.

Lambert já havia chamado a atenção para os estudos sobre a atitude linguística. Em seu trabalho, definiu atitude como "a manifestação de preferências e convenções sociais acerca do status e prestígio de seus usuários" (LAMBERT, 1967), considerando que os falantes que ocupam posições sociais mais prestigiadas determinam as atitudes linguísticas das "comunidades de fala". Além disso, postulou que a atitude é constituída de três elementos de mesmo nível: cognitivo, afetivo e conativo que, por sua vez, são os mesmos apontados pela linha teórica mentalista, citada por Cyranka. Aguilera (2008, p. 106) retomando estes postulados, esclarece que o primeiro pertence ao domínio do saber e das crenças; o segundo, à dimensão da valoração, e o terceiro, à conduta.

Revisitando os Conceitos de Crenças e Atitudes Linguísticas Presentes nos Documentos Federais e nas Escolas

Conforme já mencionado anteriormente, os PCN expõem uma orientação de ensino de língua portuguesa voltada para o uso, para a interação e, por conseguinte, para a consideração da diversidade linguística, já que "avalia" que o estudo desta característica da língua é fundamental para a formação da consciência linguística, bem como para o desenvolvimento da competência comunicativa do estudante, uma vez que este se encontra em um meio social marcado pela diversidade em suas mais diversas facetas.

No entanto, apesar de os PCN constituírem-se como documento oficial, relevante e socialmente legitimado quanto ao objetivo de orientar os professores em suas práticas pedagógicas, ao se ter contato com o ensino da língua portuguesa em muitas escolas brasileiras, percebe-se uma grande diferença entre os dizeres dos PCN e o que de fato é trabalhado nessas escolas. Isso acontece porque, embora já há algumas décadas possamos observar a implantação maciça das teorias linguísticas nas Instituições de Ensino Superior no Brasil - que vieram criticar, revisar e reformular as milenares noções e prescrições da doutrinária tradição gramatical -, em sala 
de aula, estas milenares noções e prescrições da doutrina gramatical continuam, tradicionalmente, ocupando seus lugares (cf. BAGNO, 2002). Essa tradição está associada ao que os professores acreditam (suas crenças) sobre o que é ensinar língua portuguesa.

Tal tradição, mesmo se mostrando obsoleta e ineficiente - prova concreta disso são os baixos resultados de desempenho alcançados pelo Brasil em avaliações oficiais (nacionais e internacionais), como SAEB ${ }^{5}$, ENEM $^{6}$, PISA $^{7}$ 2000, 2003, 2006; IDEB 2009 -, parece se manter “intocável" devido, como ressalta Marcos Bagno, à expectativa, ou seja, à crença vigente na sociedade em geral, sobretudo entre os pais dos alunos, de que "a escola ensine 'português' (entenda-se: gramática normativa) exatamente do mesmo modo como eles, pais, aprenderam em sua época de escola" (BAGNO, 2002, p. 16).

Entretanto, entendendo que a língua é um dos elementos primordiais para a constituição da identidade de uma nação, é direito de seus falantes reconhecê-la em sua realidade dinâmica e heterogênea e que, portanto, varia e muda no tempo e no espaço. De acordo com os PCN, o objetivo principal da aula de Língua Portuguesa é o de formar cidadãos e, se o cidadão deve

${ }^{5}$ Sistema de Avaliação da Educação Básica composto por dois processos: a Avaliação Nacional da Educação Básica (Aneb) e a Avaliação Nacional do Rendimento Escolar (Anresc). A primeira é realizada por amostragem das Redes de Ensino em cada unidade da Federação e tem foco nas gestões dos sistemas educacionais. Por manter as mesmas características, recebe o nome do Saeb em suas divulgações. Já a segunda é mais extensa e detalhada que a Aneb e tem foco em cada unidade escolar. Por seu caráter universal, recebe o nome de Prova Brasil em suas divulgações.

${ }^{6}$ Exame Nacional do Ensino Médio criado para avaliar o desempenho do estudante ao fim da educação básica, a fim de contribuir para a melhoria da qualidade desse nível de escolaridade. A partir de 2009 passou a ser utilizado também como mecanismo de seleção para o ingresso no ensino superior, além de ser utilizado também para o acesso a programas oferecidos pelo Governo Federal, como o Programa Universidade para Todos - ProUni.

7 Programa Internacional de Avaliação de estudantes. Resultados disponíveis em $<$ http://bit.do/cfrd3>.

8 Índice de Desenvolvimento da Educação Básica. Resultados disponíveis em $<$ http://bit.do/cfrd5 $>$. 
... conhecer características fundamentais do Brasil nas dimensões sociais, materiais e culturais como meio para construir progressivamente a noção de identidade nacional e pessoal e o sentimento de pertença ao país; conhecer e valorizar a pluralidade do patrimônio brasileiro [...] posicionando-se contra qualquer discriminação baseada em diferenças culturais, de classe social, de crenças, de sexo, de etnia ou outras características individuais e sociais. (BRASIL, 1998, p. 7),

então, o domínio da língua é, sem dúvida, uma das condições para a atuação do sujeito na esfera social. Logo, oferecer ao aluno um ensino restrito à abordagem da norma padrão, que se encerra na apresentação de regras gramaticais e análises de elocuções descontextualizadas, negando ou desconsiderando a variação da língua, se mostra, no mínimo, ineficiente na formação de sujeitos cidadãos.

Afinal, o estudante deve ser visto como um ser social que necessita interagir nas mais diversas situações e contextos e, para isso, é fundamental que seja levado a (re)conhecer as variedades da língua, percebendo que esta lhe oferece, o tempo todo, formas mais e menos adequadas às situações comunicativas em que se encontra. Sendo assim, a crença do "certo vs. errado" perde espaço para as noções de mais e menos adequado aos diversos contextos de uso, uma vez que devemos trabalhar com a concepção real de língua, ou seja, heterogênea, e não mais com uma concepção ideal de língua, essencialmente homogênea. Por isso, é essencial que essa crença e as atitudes linguísticas oriundas dela e tradicionalmente presentes nas escolas - também trazidas pelos alunos e presentes na família desses alunos - sejam reconstruídas. Esse é um dos papéis do "novo" professor de língua portuguesa. Como podemos verificar, o próprio documento federal brasileiro prevê essa mudança de atitude linguística, como se lê nos PCN:

... a questão não é falar certo ou errado, mas saber qual forma de fala utilizar, considerando as características do contexto de comunicação, ou seja, saber adequar o registro às diferentes situações comunicativas. É saber coordenar satisfatoriamente o que falar e como fazê-lo, considerando a quem e por que se diz determinada coisa. (BRASIL, 1998, p. 26). 


\section{Resultados de Pesquisas já Realizadas sobre Crenças e Atitudes Linguísticas}

Há diversos trabalhos já realizados sobre atitudes linguísticas. Os primeiros, segundo Cyranka (2007), são datados de 1960, como o de Lambert et al. (1960) que analisa a avaliação de canadenses que falavam francês e inglês a fim de conhecer os julgamentos deles em relação à própria língua. Desse trabalho, os autores concluíram que os canadenses falantes tanto de francês quanto de inglês valorizaram mais a língua inglesa em detrimento da francesa.

Labov (1972, p. 19), igualmente, ocupou-se com o estudo das atitudes linguísticas e desenvolveu uma pesquisa em que analisou a diferença de tratamento que os falantes de inglês da Ilha Martha's Vineyard - situada na costa de Massachusetts - conferiam às pronúncias dos ditongos [ay] e [aw]. Os resultados evidenciaram os fatores sociais como influentes na avaliação do falante em relação à variedade, visto que havia nessa ilha dois grupos que mantinham interesses distintos: o primeiro tentava permanecer na ilha e, por isso, avaliou melhor a variedade local, enquanto o segundo pretendia morar no continente e, por esta razão, avaliou de maneira mais positiva a variedade do continente.

Já Santos (1976) investigou a avaliação de alunos residentes em um bairro da Zona Norte carioca sobre seis variantes fonéticas distintas. São elas: a presença ou não de consoante final em vocábulos oxítonos [fal'a]; a palatalização ou não da lateral antes de vogais anteriores [kui'é]; a nasalização ou não, em sílaba átona final, de vocábulos, como em [nuve]; o desenvolvimento de vogal anterior nos grupos consonantais em que o segundo elemento é oclusivo [pineu]; a presença ou ausência de elemento nasal em sílabas simples iniciais de vocábulos [ignorãti].

Para o desenvolvimento da pesquisa, o autor analisou a avaliação de 115 estudantes dos anos finais do Ensino Fundamental e de 18 adultos, pais dos alunos. Com os resultados obtidos, Santos constatou que os alunos provenientes de classe social menos prestigiada manifestaram preconceito em relação à variedade linguística de seus pais, ao contrário do que ocorreu com os alunos de classe social mais prestigiada, que revelaram uma tendência a repetir a postura dos pais. Sendo assim, por meio desses resultados, podemos 
inferir que, provavelmente, a escola não trabalhou as variedades linguísticas no sentido de conscientizar os alunos acerca do valor social delas e do uso adequado de cada uma conforme o contexto em que exige o seu emprego.

Amaral (1989) também se interessou pela questão e desenvolveu, em Brasília, uma pesquisa em que analisou as atitudes de professores de Português sobre a variedade não padrão de alunos provenientes de duas regiões distintas de Brasília, uma central e outra periférica. Os resultados demonstraram que os professores possuem maior apreço pela variedade da classe média, repetindo, mais uma vez, a constatação de que o preconceito linguístico está relacionado ao preconceito socioeconômico e cultural.

Cyranka (2007), por sua vez, investigou a avaliação de alunos da oitava série $^{9}$ do Ensino Fundamental de escolas públicas de Juiz de Fora em relação a três variedades linguísticas: a rural, a rurbana e a urbana. Além disso, a autora também analisou a correlação existente entre as crenças dos professores e as crenças e atitudes desses alunos com a intenção de detectar a interferência "no desenvolvimento, no aluno, de competências de uso da variedade culta". Dessa pesquisa, a autora inferiu que

Os resultados evidenciaram alunos em conflito entre a aprovação de sua variedade lingüística (teste de atitudes) e a declaração de que não sabem escrever, nem falar bem (teste de crenças): os alunos da oitava série estão inibidos em relação ao uso de sua própria língua e condicionam o desenvolvimento dessas competências a crenças equivocadas, como aprender regras de gramática e de ortografia. Daí sua baixa auto-estima e o preconceito lingüístico às vezes até mesmo contra sua própria fala, que consideram menos correta do que a escrita. Isso pode constituir indício da insuficiência do trabalho com a oralidade na escola, instituição com a qual, no entanto, contam para lhes suprir o que consideram suas deficiências linguísticas. (CYRANKA, 2007, p. 6).

Também Aguilera (2008, p. 109) focalizou o estudo das crenças e atitudes linguísticas por considerá-lo preterido a outros campos investigados.

${ }^{9}$ Atual nono ano do Ensino Fundamental II. 
Em seu artigo "Crenças e atitudes lingüísticas: o que dizem os falantes das capitais brasileiras", a autora relata a experiência em que analisou as atitudes sociolinguísticas de falantes de 25 capitais brasileiras em relação à sua própria variedade linguística e à variedade do outro. Dentre as conclusões que apresenta, destaca a influência das crenças nas atitudes e o influxo das variáveis idade, nível de escolaridade, sexo e região de origem nos resultados.

Recentemente, na região do Triângulo Mineiro, no Brasil, mais especificamente na cidade de Uberaba-MG, Barbosa e Cuba (2015) realizaram um estudo sobre atitudes e crenças linguísticas de alunos do Ensino Médio em escolas públicas daquela cidade. Em relação ao teste de crença, as autoras aplicaram um questionário composto por 27 perguntas. De maneira geral, os resultados mostraram que os alunos das escolas de Uberaba têm orgulho de seu modo de falar, apesar de considerarem bonitas outras maneiras de falar; acreditam que a língua escrita é mais correta que a falada e que, portanto, escrevem melhor do que falam; pensam que uma das funções da escola é corrigir a fala dos alunos e também que a escola onde estudam os ajuda a escrever e a falar corretamente em diferentes situações; pensam que os adultos falam melhor que os jovens; consideram a linguagem dos livros mais bonita e melhor do que seu próprio "jeito de falar"; acreditam que falar bem é tão importante quanto escrever bem; demonstraram que um professor de Português competente deve falar de acordo com as regras da gramática; acreditam que seu professor de Português fala corretamente e que ele mostra, nas aulas, as diferentes maneiras de falar e, por fim, afirmaram que mudam sua maneira de falar de acordo com a situação em que estão.

Tais resultados também foram semelhantes aos de pesquisas já citadas, como a de Cyranka (2007), na qual os alunos do Ensino Fundamental de Juiz de Fora também demonstraram pensar que há maneiras de falar "mais bonitas" do que a deles e demonstram preconceito linguístico em relação à própria fala e a de outras variedades. Tudo isso, portanto, mostra que há ainda um grande trabalho a ser realizado na escola no que se refere às discussões a respeito das variedades linguísticas, bem como às reflexões sobre a língua, envolvendo fala, leitura e escrita. 


\section{Ensino Reflexivo e a Prática da Pedagogia Culturalmente Sensível}

É importante destacar que todas essas informações e reflexões que estão sendo aqui expostas vêm nos atentar sobre a visão de língua dos falantes e para o fato de que os PCN sugerem um ensino de Língua Portuguesa reflexivo (cf. HALLIDAY; McINTOSH; STREVENS, 1974) a partir de uma prática pedagógica culturalmente sensível ${ }^{10}$.

Em relação aos PCN, apesar de se reconhecer a legitimidade de tal documento, respaldado por conhecimentos linguísticos modernos, sabemos que, na prática, estamos muito distantes de um ensino predominantemente reflexivo e envolto por essa pedagogia culturalmente sensível, e isso acontece por vários motivos, dentre os quais destacaremos três por acreditarmos que são os mais contundentes:

$\left.1^{\circ}\right)$ Há uma crença social muito forte sobre a língua, presente em diversas instâncias da sociedade, especialmente na escola e na família, e sobre o que "é ensinar Língua Portuguesa", orientada por um viés ideológico elitista e conservador, que acaba por contribuir para a manutenção de um ensino tradicional pautado na dita "norma-padrão"11, centrado na escrita, que despreza e/ou desvaloriza toda e qualquer realização linguística que não se

\footnotetext{
${ }^{10} \mathrm{O}$ conceito de pedagogia culturalmente sensível (A culturally responsive pedagogy) foi proposto por Frederick Erickson, em 1987, dentro da tradição dos estudos etnográficos interpretativos que focalizam a vida no interior das escolas e a relação entre a sociabilização das crianças no lar e nas escolas. Segundo Erickson, tal proposta pedagógica consiste num tipo especial de esforço por parte da escola que pode reduzir as dificuldades de comunicação entre professores e alunos e prevenir a gênese de conflitos que se movem rapidamente além dos mal entendidos e que podem evoluir para confrontos mais sérios na troca de identidades entre alunos e professores.

${ }^{11}$ Aqui utilizamos o termo "norma-padrão" entendida como uma norma abstrata e singular e que, portanto, não deve (e não deveria) ser objeto de estudo das e nas aulas de língua portuguesa dos ensinos fundamental e médio. Consideramos que seja papel da escola, a partir de uma abordagem sociolinguística de língua, isto é, considerando as diferentes variedades da língua, dar ênfase ao estudo da "norma culta", concreta e plural, já que esta, em suas diferentes nuances distribuídas num continuum de formalidade, condiz com a língua de fato utilizada pelo falante em contextos mais monitorados, tanto na fala quanto na escrita.
} 
enquadre nas prescrições da língua consideradas "corretas", "bonitas" e "elegantes". Como exemplo disso, podemos citar falas de estudantes do último ano do Ensino Médio, da faixa etária de 16-18 anos, de uma escola pública de Uberaba, sobre o falar mineiro, e que, apesar de já estarem concluindo a Educação Básica, ainda possuem "crenças linguísticas" equivocadas, ligadas a noções de "certo vs. errado" e "melhor vs. pior" em relação à sua língua materna ${ }^{12}$ :

\section{Fragmento 1}

I: fala errado eu acho que é com muitas gírias... jeito mineiro é um jeito errado de fala... (Inf. 2 - Escola A)

\section{Fragmento 2}

I: os mineiros... os mineiros falam errado.

E: cê acha que os mineiros falam errado?

I: eu acho, muito errado eles... a gente fala. (Inf. 10 - Escola B)

\section{Fragmento 3}

I: falar corretamente é aquela linguagem que a gente usa na... gramatica... uma linguagem muito formal... linguagem errada é a linguagem que a gente usa gírias ... a linguagem que a gente fala com os amigos... rede social... (inf. 4-escola B)

$\left.2^{\circ}\right)$ Embora, há algumas décadas, as faculdades de Letras de diversas universidades brasileiras tenham acrescentado aos seus currículos disciplinas que abordam questões atreladas à variação linguística - tanto do ponto de vista teórico quanto ao aplicado -, contribuindo, assim, para a formação de professores mais conscientes e críticos quanto ao aspecto dinâmico e heterogêneo das línguas naturais ${ }^{13}$, acreditamos que os recém-professores,

\footnotetext{
${ }^{12}$ Fragmentos extraídos da pesquisa de Barbosa e Cuba (2015).

${ }^{13} \mathrm{E}$, diante dessa nova possibilidade de formação, acabam atentando-se, inclusive, para a forma como o ensino de língua portuguesa tem sido realizado em nosso país, apontando seus maiores problemas e obstáculos e refletindo acerca de caminhos alternativos e necessários que precisam ser tomados.
} 
ao entrarem em sala de aula, acabam enfrentando dificuldades severas quando tentam colocar em prática a teoria a qual tiveram acesso em sua formação, tanto em função da resistência à mudança por parte das escolas, quanto dos pais dos alunos - ainda muito avessos à mudança na forma de se realizar o ensino de Língua Portuguesa. Isso está diretamente relacionado com o que afirmam Faraco e Zilles na introdução do livro Pedagogia da variação linguística: lingua, diversidade e ensino:

O senso comum tem escassa percepção da língua como um fenômeno heterogêneo que alberga grande variação e está em contínua mudança. Por isso, costuma folclorizar a variação regional; demoniza a variação social e tende a interpretar as mudanças como sinais de deterioração da língua. (FARACO; ZILLES, 2015, p. 7).

Questões como essas podem ser evidenciadas nos fragmentos abaixo, extraídos de falas de alunos do último período do curso de Licenciatura em Letras (formandos em dezembro de 2014), que estão se inserindo nas escolas como professores de língua portuguesa ${ }^{14}$ :

\section{Fragmento 4}

aí é engraçado é meio paradoxo né/ a gente fala que não tem... que não pode usar o termo errado ou o correto mas é... infelizmente ou felizmente... depende do ponto de vista da pessoa a gente tem que aceitar e admitir que a sociedade exige e não tem jeito... ela exige e ela quer um profissional que saiba se portar em diferentes situações... primeiro o que é que vem primeiro? é a aparência... não adianta falar que não mas eu penso que a aparência vem em primeiro lugar... do que vai adiantar eu sair da faculdade ou mesmo eu não estando cursando... pode ser meu pai por exemplo que não tem o ensino médio completo que for pra uma entrevista de trabalho e for de qualquer jeito ou que fale inadequadamente... a gente sabe que a sociedade vai condenar esse tipo de falante 0 sim acho que a gente

\footnotetext{
${ }^{14}$ Fragmentos extraídos do corpus de Santos e Barbosa (2014).
} 
tem que saber se portar em situações formais e dominar a norma culta $O$ (entrevistado G, último ano do curso de Letras)

\section{Fragmento 5}

[...] antes de entrar na faculdade eu tinha um senso comum mesmo... eu achava que português era só gramática mas agora eu vejo que não... o duro é como levar isso pra sala de aula, o diretor, o coordenador, os pais, não deixa... questionam. (entrevistado B, último ano do curso de Letras)

Por outro lado, já podemos observar falas (crenças) como:

\section{Fragmento 6}

[...] um bom professor se ele vai explicar sobre as variedades linguísticas caso contrário ele não é um bom professor porque ele tá privilegiando só uma variedade e num tá reconhecendo as outras. (entrevistado E, último ano do curso de Letras)

Cabe destacar que, assim como Bagno (2002, p. 79), acreditamos ser

... preciso distinguir aquilo que o futuro professor de língua vai estudar na universidade e aquilo que ele vai ensinar em sala de aula. Os estudantes de Letras têm de conhecer profundamente a tradição gramatical, junto com as críticas que têm sido feitas a essa tradição pelas diversas correntes da lingüística moderna. O professor de português tem de receber uma sólida formação científica, como a de qualquer outro profissional que sai da universidade para o mundo do trabalho. Mas isso não quer dizer que ele vá transmitir a seus alunos exatamente aquilo que aprendeu na universidade.

$3^{\circ}$ ) Por fim, outro ponto que destacamos é um cenário vivenciado por alunos recém-formados em Letras, como o do fragmento 6 acima, que acreditam no ensino pautado na diversidade linguística e encontram escolas receptivas a um ensino de Língua Portuguesa mais atento às sugestões dos PCN, porém têm dificuldade de estabelecer uma ponte entre a teoria linguística 
estudada durante a graduação e a prática a ser estabelecida nas salas de aula. Essa dificuldade em aliar a teoria linguística à prática pode ser observada na atividade proposta aos alunos do curso de Licenciatura em Letras, que já estudaram Sociolinguística, pelas coordenadoras do PIBID/CAPES ${ }^{15}$, subprojeto de Língua Portuguesa de uma universidade pública da região sudeste do Brasil, que consistia na elaboração de atividades que visassem a apresentar o conceito variação linguística a alunos do Ensino Médio. Para realizar tal atividade, apesar de os graduandos gostarem da ideia, fizeram afirmações como:

\section{Fragmento 7}

... é difícil elaborar uma atividade sem cair no preconceito linguístico...

\section{Fragmento 8}

... não sei onde procurar atividades...

\section{Fragmento 9}

... os livros didáticos só trazem tirinhas, qual outro material posso usar?

Essas atividades, muitas vezes, reproduziram outras já existentes em materiais didáticos, como as que "concretizam" a falsa crença da visão dicotômica de "formal vs. informal" ou de "fala vs. escrita", por exemplo, sem levar em consideração o continuum da formalidade e o da fala e escrita, já apontados por diferentes linguistas, como Marcuschi (2007a). A seguir,

${ }^{15}$ Pibid (Programa Institucional de Bolsa de Iniciação à Docência), fomentado pela CAPES, é uma iniciativa para o aperfeiçoamento e a valorização da formação de professores para a educação básica. O programa concede bolsas a alunos de licenciatura participantes de projetos de iniciação à docência desenvolvidos por Instituições de Educação Superior (IES) em parceria com escolas de educação básica da rede pública de ensino. Os projetos devem promover a inserção dos estudantes no contexto das escolas públicas desde o início da sua formação acadêmica para que desenvolvam atividades didático-pedagógicas sob orientação de um docente da licenciatura e de um professor da escola (Fonte: CAPES. Disponível em <http://bit.do/cfreg>.). 
apresentam-se algumas amostras dessas atividades, que ilustraram o que acabamos de afirmar:

\section{Atividade $1^{16}$}

Reescreva o texto abaixo (escrito numa linguagem informal) para uma linguagem formal

\section{Atividade 2}

Leia as frases abaixo e digam se são formal ou informal

Muitos ainda consideraram "gírias", na elaboração de suas atividades, expressões como "pra”, "a gente” e marcas de ausência de concordância. Isso demostra que, apesar de os alunos estudarem Sociolinguística, ainda trazem consigo crenças bastante equivocadas do ponto de vista linguístico e tradicionalmente presentes no ensino de língua portuguesa.

Diante disso, fica evidente que este cenário precisa ser alterado em prol de um ensino de língua mais moderno, democrático, interativo, crítico e reflexivo, respaldado por uma pedagogia culturalmente sensível. Para isso, acreditamos que os principais atores envolvidos no que diz respeito ao ensino de língua portuguesa devam ser considerados, ou seja, a escola, os alunos, os professores e, também, a família. Afinal, diferentemente das outras disciplinas, o aluno já chega à escola dominando o objeto de estudo referente às aulas de Português, ao menos em manifestações de oralidade da variedade familiar, apre(e)ndida no seio familiar, naturalmente.

Precisamos ouvir esses atores. Precisamos saber quais são suas impressões acerca do ensino de língua portuguesa no Brasil. Precisamos saber o que acreditam ser os objetivos deste ensino e, sobretudo, quais suas expectativas em relação ao estudo de sua própria língua. Só assim poderemos pensar em iniciativas de fato eficientes no que tange ao já referido ensino de língua portuguesa "mais moderno, democrático, interativo, crítico e reflexivo". Um ensino que garanta ao falante nativo do português, ao término do Ensino Médio, habilidade, adequação e segurança nos mais variados usos de sua língua, tanto em contextos de fala quanto de escrita.

\footnotetext{
${ }^{16}$ Enunciado adaptado.
} 
Afinal, assim como Faraco e Zilles (2015, p. 9), acreditamos que

... não se trata apenas de desenvolver uma pedagogia que garanta o domínio das práticas socioculturais e das respectivas variedades linguísticas. Considerando o grau de rejeição social das variedades ditas populares, parece que o que nos desafia é a construção de uma cultura escolar aberta à crítica da discriminação pela língua e preparada para combatê-la, o que pressupõe uma adequada compreensão da heterogeneidade linguística do país, sua história social e suas características atuais.

Nesse sentido, mais uma vez destacamos as contribuições da Sociolinguística ao ensino de língua portuguesa por nós almejado e defendido neste artigo:

- Respaldo teórico-metodológico para compreender a variação linguística como um fato da língua e não como um problema, uma deteriorização ou "perigo";

- Definição de conceitos básicos para o tratamento adequado dos fenômenos variáveis, pondo um ponto final à nociva e equivocada "doutrina do erro";

- Reconhecimento da pluralidade linguística brasileira formada por diferentes línguas (autóctones, alóctones, LIBRAS) e variedades de língua em convivência no seio social;

- Identificação de crenças e atitudes linguísticas diretamente ligadas ao ensino-aprendizado da língua portuguesa;

- Entendimento do "prestígio encoberto" (LABOV, 1972) e suas implicações ao ensino da norma culta;

- Compreensão dos conceitos de norma, norma culta (concreta e plural), norma padrão (idealizada e singular) ${ }^{17}$;

- Compreensão dos conceitos de variedades cultas e variedades populares;

- Conceituação de registro e modalidade (instâncias distintas);

${ }^{17}$ Conforme definições de Faraco (2008). 
- Reconhecimento de que a fala e a escrita apresentam normas diferentes e se realizam num continuum de formalidade (MARCUSCHI, 2007a) ou dialetal (BORTONI-RICARDO, 2005);

- Reconhecimento das semelhanças entre as variedades cultas e populares;

- Pesquisas sociolinguísticas de caráter descritivo que nos possibilitam (re)conhecer a língua em uso, apontando para uma configuração considerando-se diferentes fenômenos em diversos níveis linguísticos - bastante distinta daquela prescrita pelas gramáticas normativas escolares e pelos livros didáticos ${ }^{18}$.

Parece-nos, portanto, muito claro que exemplos não nos faltam para demonstrar o quão significativas e relevantes são as contribuições da Sociolinguística ao entendimento e à prática do ensino de língua portuguesa em nossas salas de aula de Ensino Fundamental e Médio. Além disso, pretendemos, novamente, com todos esses tópicos anteriormente apresentados, demonstrar que suas contribuições são, de fato, possíveis à prática docente, transcendendo, portanto, a discussões meramente teóricas e descritivas da língua.

\section{Considerações Finais}

Buscamos destacar, neste artigo, o quão desafiador é pensar numa concepção sociolinguística de ensino de língua portuguesa no Brasil. Mas,

\footnotetext{
${ }^{18}$ Para citar apenas dois exemplos, temos o trabalho de Marine (2009), que aborda a questão da configuração do sistema pronominal dos demonstrativos que se mostra binário no Português Brasileiro Contemporâneo (esse vs. aquele) e não ternário (este $v s$. esse $v s$. aquele), tal como prescrito nas gramáticas normativas. Outro exemplo interessante do uso de nossa língua oriundo de estudos de caráter sociolinguístico, e que deveria ser abordado de modo reflexivo em sala de aula, diz respeito à nova configuração dos pronomes pessoais sujeitos no Português Brasileiro Contemporâneo apontado por Duarte (2013), representada pelas formas eu/ tu, você/ ele, ela/ nós, a gente/ vocês/ eles, elas e não da maneira como é "ensinada" nas salas de aula, (eu/tu/ele/nós/vós/eles). Como podemos observar, tal quadro pronominal mudou e, assim, atualmente podemos perceber que algumas formas caíram em desuso, ao passo que outras foram incorporadas, promovendo, com isso, inclusive, uma redução no paradigma verbal.
} 
mais desafiador ainda, é se propor a praticar um ensino sociolinguístico em um país tão diverso do ponto de vista social, econômico, étnico, cultural e linguístico. Isso exige muito estudo e pesquisa, pois só assim os professores conquistarão segurança para desenvolver um ensino de língua reflexivo, plural e culturalmente sensível em suas salas de aula.

O primeiro passo para se alcançar tal objetivo - e possivelmente um dos mais difíceis - é se desvincular de crenças equivocadas e de atitudes obsoletas atreladas ao ensino/aprendizagem do Português. Acreditamos que estamos vivendo um momento ímpar no que se refere ao ensino de língua portuguesa em nosso país. Das discussões teóricas, temos caminhado rumo a mudanças de ordem prática, procurando, de fato, mediar os saberes linguísticos - até há pouco limitados ao diálogo entre pares dos grandes centros de pesquisas das nossas universidades - aos professores da escola básica.

Isso tem sido acontecido, principalmente, por meio da elaboração de material didático mais sintonizado com as sugestões dos PCN, pela reformulação dos projetos políticos-pedagógicos e das grades curriculares de diversos cursos de Letras de nosso país, por meio também de projetos extensionistas de formação de professores, os quais têm unido docentes e discentes de Letras a professores dos Ensinos Fundamental e Médio da rede pública, além, é claro, da implementação, em agosto de 2013, pelo Governo Federal, do Mestrado Profissional em Letras, desenvolvido em diversas instituições de Ensino Superior Público do país, cujo público são justamente os professores da rede pública do Ensino Básico.

Diante de todas as questões e reflexões que trouxemos neste artigo, acreditamos que (re)conhecer, refletir, questionar e se posicionar quanto à forma como o ensino de Português tem acontecido no Brasil, bem como interar-se das orientações dos PCN de Língua Portuguesa é imperativo a todos aqueles que se dedicam ao estudo e ao ensino/aprendizagem de nossa língua frente às diversidades social, cultural e linguística brasileiras. Cabe ressaltar que, embora a publicação dos PCN date de quase vinte anos (BRASIL, 1997, 1998), seu conteúdo mostra-se bastante atual e pertinente às multifacetadas demandas das salas de aula de nosso país. Por fim, como já dito nesse artigo, acreditamos também que estamos vivendo um momento muito peculiar no que se refere ao ensino de língua portuguesa no Brasil, já 
que temos encontrado espaço e oportunidades para estabelecer vínculos palpáveis entre os saberes teóricos da linguística moderna com as práticas a serem implementadas em sala de aula. Aproveitemos esse momento. Assim, e só assim, estaremos construindo um ensino sociolinguístico de língua portuguesa no Brasil.

\section{Referências}

AGUILERA, V. A. Crenças e atitudes lingüísticas: o que dizem os falantes das capitais brasileiras. Estudos lingüísticos, São Paulo, v. 37, n. 2, p. 105-112, maio/ago. 2008.

AMARAL, A. M. G. Reações subjetivas de professores de português ao dialeto nãopadrão. 1989. Dissertação (Mestrado em Linguística) - Universidade de Brasília, Brasília.

BARBOSA, J. B.; CUBA, D. L. Crenças e atitudes linguísticas de alunos do ensino médio em escolas públicas de Uberaba. Todas as Letras, São Paulo, v. 17, n. 1, p. 73-90, jan./abr. 2015. Disponível em: <http://bit.do/cftij>. Acesso em: 10 jul. 2015.

BAGNO, M. O que é letramento? Letramento e gêneros textuais. In: BAGNO, M.; STUBBS, M.; GAGNÉ, G. (Org.). Lingua materna: letramento, variação \& ensino. São Paulo: Parábola, 2002. p. 51-58.

BARCELOS, A. M. F; ABRAHÃO, M. H. V. Crenças e ensino de línguas: foco no professor, no aluno e na formação de professores. Campinas: Pontes, 2006.

BORTONI-RICARDO, S. M. Nós cheguemo na escola, e agora? São Paulo: Parábola, 2005.

BRASIL. Ministério da Educação. Parâmetros Curriculares Nacionais: Língua Portuguesa. Brasília: MEC, 1997.

BRASIL. Ministério da Educação. Parâmetros Curriculares Nacionais: Língua Portuguesa. Brasília: MEC, 1998. 
CAVALCANTI, M. C. Estudos sobre educação bilíngüe e escolarização em contextos de minorias lingüísticas no Brasil. DELTA, São Paulo, v. 15, n. esp., p. 385-417, 1999. Disponível em: <http://bit.do/cftkz>. Acesso em: 15 out. 2009.

COELHO, P. O tratamento da variação lingüistica no livro didático de Português. 2007. Dissertação (Mestrado em Linguística) - Universidade de Brasília, Brasília.

CYRANKA, L. F. M. Atitudes lingüisticas de alunos de escolas públicas de Juiz de Fora-MG. 2007. Tese (Doutorado em Estudos Linguísticos) Universidade Federal Fluminense, Niterói.

CYRANKA, L. F. M.; RONCARATI, C. Crenças de professores e alunos de português de escolas públicas de Juiz de Fora-MG. In: RONCARATI, C.; ABRAÇADO, J. (Org.). Português brasileiro II: contato lingüístico, heterogeneidade e história. Rio de Janeiro: FAPERJ; EdUFF, 2008. p. $170-191$.

DUARTE, M. E. L. O papel da sociolinguística na descrição da gramática da escrita contemporânea. In: MARTINS, M. A.; TAVARES, M. A. (Org.). Contribuições da sociolinguistica e da linguística histórica para o ensino de língua portuguesa. Natal: EDUFRN, 2013. p. 115-140.

FARACO, C. A. Norma Culta Brasileira: desatando alguns nós. São Paulo: Parábola, 2008.

FARACO; C. A.; ZILLES, A. M. S. Introdução. In: ZILLES, A. M. S; FARACO; C. A. (Org.). Pedagogia da variação linguística: língua, diversidade e ensino. São Paulo: Parábola, 2015. p. 7-15.

GNERRE, M. Linguagem, escrita e poder. 4. ed. São Paulo: Martins Fontes, 1998.

HALLIDAY, M. A. K.; McINTOSH, A.; STREVENS, P. As ciências lingüísticas e o ensino de línguas. Tradução Myriam F. Morau. Petrópolis: Vozes, 1974. 
LABOV, W. Sociolinguistic patterns. Philadelphia: University of Pennsylvania Press, 1972.

LABOV, W. Estágios na aquisição do inglês $S T A N D A R D$. Tradução Luiza Leite Bruno Lobo. In: FONSECA, M. S. V; NEVES, M. F. Sociolingüistica. Rio de Janeiro: Eldorado, 1974. p. 49-85. (Coleção Enfoque).

LAMBERT, W. E. A social psychology of bilingualism. Journal of Social Issues, v. 23, p. 91-109, 1967.

LAMBERT, W. E. et al. Evaluation reactions to spoken languages. Journal of Abnormal Social Psychology, n. 60, p. 44-51, 1960.

MANINI, D. A gramática e os conbecimentos linguísticos em livros didáticos de língua portuguesa para o ensino fundamental II (5 a a $8^{a}$ séries). 2009. Dissertação (Mestrado em Linguística Aplicada) - Universidade Estadual de Campinas, Campinas.

MARCUSCHI, L. A. Da fala para a escrita: atividades de retextualização. 8. ed. São Paulo: Cortez, 2007a.

MARCUSCHI, L. A. Cognição, linguagem e práticas interacionais. Rio de Janeiro: Lucerna, 2007b.

MARINE, T. de C. Um estudo sócio-discursivo do sistema pronominal dos demonstrativos no português contemporâneo. 2009. Tese (Doutorado em Linguística e Língua Portuguesa) - Universidade Estadual Paulista, Araraquara.

MARTINS, M. A.; VIEIRA, S. R.; TAVARES, M. A. Ensino de português e sociolinguistica. São Paulo: Contexto, 2014.

MONDADA, L. De l'analyse des représentations à l'analyse des activités descriptives en contexte. Cahiers de Praxématique, v. 31, p. 127-147, 1998.

MORAIS, C. G. Os limites e os alcances do tratamento da diversidade e variação linguísticas em livros didáticos de Português. 2014. Tese (Doutorado em LInguística) - Universidade Estadual de Campinas, Campinas. 
RODRIGUES, S. O português não padrão no universo de livros didáticos do ensino médio: posições discursivas. 2010. Dissertação (Mestrado em Estudos de Linguagem) - Universidade Federal do Mato Grosso, Cuiabá.

SANTOS, E. Mobilidade social e atitudes lingüisticas. Rio de Janeiro: UFRJ; Museu Nacional, 1976.

SANTOS, E. Certo ou errado? Atitudes e crenças no ensino da língua portuguesa. Rio de Janeiro: Graphia, 1996.

SANTOS, N. F.; BARBOSA, J. B. Crenças e atitudes linguísticas de alunos do curso de Letras da cidade de Uberaba-MG. 2014. Trabalho de Conclusão de Curso (Graduação em Letras) - Universidade Federal do Triângulo Mineiro, Uberaba.

SCHERRE, M. M. P. Doa-se lindos filhotes de poodle: variação lingüística, mídia e preconceito. São Paulo: Parábola, 2005.

TRAVAGLIA, L. C. Gramática e interação: uma proposta para o ensino de gramática. 13. ed. São Paulo: Cortez, 2009.

WEINREICH, U.; LABOV, W.; HERZOG, M. Fundamentos empíricos para uma teoria da mudança lingüística. 2. ed. Tradução Marcos Bagno. São Paulo: Parábola, 2009 [1968]. 